\title{
Zinc and iron removal from chromium(III) passivation baths by solvent extraction with Cyanex 272
}

\author{
F.J. Alguacil ${ }^{\mathrm{a}, *}$, N. Diban ${ }^{\mathrm{b}}$, A. Urtiaga ${ }^{\mathrm{b}}$ \\ ${ }^{a}$ Centro Nacional de Investigaciones Metalurgicas (CSIC), Avda. Gregorio del Amo 8, 28040 Madrid, \\ Spain, email: fjalgua@cenim.csic.es \\ ${ }^{b}$ Departamento de Ingenieria Quimica y Quimica Inorganica, Universidad de Cantabria, Avda. de los Castros s/n, \\ 39005 Santander, Spain, emails: nazely.diban@unican.es (N. Diban), ana.urtiaga@unican.es (A. Urtiaga)
}

Received 12 March 2018; Accepted 17 June 2018

\section{A B S T R A C T}

The use of Cyanex 272 for extraction of zinc and iron from industrial wastes like chromium(III) passivation baths is investigated. The extraction of the metals is studied, in batch conditions, as a function of equilibration time, temperature, diluent of the organic solution, metals and extractant concentrations and $\mathrm{pH}$ values of the aqueous solutions. Also the stripping of the metals from loaded organic phases had been investigated using sulphuric acid solutions as strippant.

Keywords: Passivation baths; Zinc; Iron; Chromium; Cyanex 272; Solvent extraction

\section{Introduction}

As a unit operation, solvent extraction had long provided its capabilities in the separation, purification, etc., in the hydrometallurgical processing of a number of metals. The successful utilization of the technology is mainly based, among others, in its operational flexibility, the possibility of the treatment of large aqueous volumes, and in the rapid processing of the solutions, few minutes, since the aqueous stream enters the extraction circuit and the metal-loaded strip solution exits from the stripping circuit. Sure, the solvent extraction operation has their cons, however, these can be minimized upon a proper operation procedure.

There are two basic sources for zinc recovery by the use of hydrometallurgy: raw materials (i.e. sphalerite) and industrial residues and effluents (i.e. electric arc furnace flue dusts and chromium passivation baths (PBs)). In most of the proposed, and used, recoveries flow-sheets, zinc solvent extraction plays a decisive role in the overall scheme due to the operational characteristics mentioned earlier. Since zinc

\footnotetext{
* Corresponding author.
}

is mostly presented in the aqueous solutions generated from these recovery processes as $\mathrm{Zn}^{2+}$, the extractants used to extract the cation are, naturally, acidic or cationic reagents, and among them, alkylphosphorus derivatives are often used [1-7]. As in all general rules, and despite the earlier, there are exceptions and in the case of zinc(II) this occurs in the treatment of spent pickling solutions, in which, basic or solvation reagents had been proposed as extractants for the various neutral species and anionic zinc(II)-chloride complexes [8-10], whereas more recently, ionic liquids had been introduced as potential zinc extractants from this chloride and other aqueous media [11-16].

The present investigation was undertaken, as a part of a whole investigation in the treatment of spent PBs, in order to investigate the performance of the solvent extraction operation in the treatment of one of this PBs [17,18]. Several parameters affecting the extraction of the main metals: zinc, iron and chromium, containing in the bath had been investigated and also the strip of the metals from metal-loaded organic solutions. As an extractant for the system, the alkylphosphinic acid with commercial name of Cyanex 272 has been used along the experimentation. Previously, Cyanex 272 was used as carrier in previous membrane experiments 
$[15,16]$, thus may be logical in its use in this work, on the other hand, though Cyanex 272 is not as stronger extractant for zinc as D2EHPA (di-2-ethylhexylphosphoric acid) is, but the strippability of Cyanex 272 phases loaded with zinc and iron is more easy done than that with D2EHPA, and in fact, iron(III) is not stripped with sulphuric acid solutions but with hydrochloric acid solutions.

\section{Experimental}

The extractant used in this investigation was obtained from Cyanex 272 (CYTEC Ind., Canada, in which active substance is bis(2,4,4-trimethylpentyl)phosphinic acid. The extractant was used without further purification. Organic diluents Shellsol D70 (Kremer Pigmente) and Solvesso 100 (Exxon Chem. Iberia, Spain) were also used without further purification. Other chemicals were of AR grade.

The spent $\mathrm{PB}$, and its diluted samples, has the compositions shown in Table 1 for zinc, total iron and total chromium.

Extraction and stripping experiments were carried out by shaking equal volumes ( $25 \mathrm{~mL}$ each phase), unless otherwise stated, of the appropriate organic and aqueous solutions in separatory funnels, for the time and at the temperature required. $\mathrm{pH}$ variation investigations on metals extraction were conducted by adding to the initial aqueous solutions known aliquots of standard $\mathrm{NaOH}$ or $\mathrm{HNO}_{3}$ solutions. Metals were analysed by atomic absorption spectrometry, whereas the $\mathrm{pH}$ of the equilibrated aqueous solutions was measured using a Crison-250 pH-meter provided with a combined electrode.

\section{Results and discussions}

\subsection{Zinc}

Experiments on the influence of contact time on zinc extraction have been carried out by shaking at $20^{\circ} \mathrm{C}$ for various lengths of time (5-60 $\mathrm{min})$ the $\mathrm{PB}$ solution and organic solutions of $10 \%$ v/v Cyanex 272 in Shellsol D70 at $\mathrm{O} / \mathrm{A}$ ratio of 1 . Results obtained showed that equilibrium is achieved within 5 min of contact $\left(56.8 \%\right.$ extraction at $\mathrm{pH}_{\mathrm{eq}}$ of 2.52).

The relationship between zinc extracted into the organic phase and the temperature was also studied, the aqueous and organic solutions used being the same as earlier. It is observed (Table 2) that there is little variation in the percentage of zinc extraction in the $12^{\circ} \mathrm{C}-50^{\circ} \mathrm{C}$ temperature range, however, zinc extraction tends to increase as the temperature increases to $50^{\circ} \mathrm{C}$. The same tendency had been observed in the extraction of a passivation bath but with

Table 1

Chemical composition of bath solutions

\begin{tabular}{llcc}
\hline Element & $\mathrm{PB}$ & $\mathrm{PB} / 2$ & $\mathrm{~PB} / 4$ \\
\hline $\mathrm{Zn}$ & $10.6 \mathrm{~g} / \mathrm{L}$ & $5.0 \mathrm{~g} / \mathrm{L}$ & $2.8 \mathrm{~g} / \mathrm{L}$ \\
$\mathrm{Fe}_{\text {total }}$ & $59.1 \mathrm{mg} / \mathrm{L}$ & $28.0 \mathrm{mg} / \mathrm{L}$ & $12.3 \mathrm{mg} / \mathrm{L}$ \\
$\mathrm{Cr}_{\text {total }}$ & $4.9 \mathrm{~g} / \mathrm{L}$ & $2.6 \mathrm{~g} / \mathrm{L}$ & $1.6 \mathrm{~g} / \mathrm{L}$ \\
\hline
\end{tabular}

$\mathrm{PB}$, undiluted bath; $\mathrm{PB} / 2$, bath diluted at $50 \% ; \mathrm{PB} / 4$, bath diluted at $75 \%$.
Table 2

Influence of temperature on the extraction of zinc

\begin{tabular}{lll}
\hline Temperature & $\mathrm{pH}_{\mathrm{eq}}$ & \% Zinc extraction \\
\hline $12^{\circ} \mathrm{C}$ & 2.2 & 43.3 \\
$50^{\circ} \mathrm{C}$ & 1.7 & 45.2 \\
\hline
\end{tabular}

Equilibration time: $10 \mathrm{~min} . \mathrm{O} / \mathrm{A}$ ratio $=1$.

nearly half the initial zinc(II) concentration that is presented here [16].

The performance of the Cyanex 272-passivation bath extraction system was studied using Shellsol D70 and Solvesso 100 as diluents for the organic phase. The organic phases were of $10 \% \mathrm{v} / \mathrm{v}$ Cyanex 272 in each diluent. Other experimental conditions were temperature $20^{\circ} \mathrm{C}$, equilibration time $10 \mathrm{~min}$ and $\mathrm{O} / \mathrm{A}$ ratio 1 .

Though in the case of Solvesso 100, zinc equilibrium extraction is also reached within 5 min of contact, the results obtained shown that the change of the diluent influences zinc extraction since the $\mathrm{pH}_{50}$ value (equilibrium $\mathrm{pH}$ value in which the metal distribution coefficient $D=1$ or $50 \%$ metal extraction) vary from 2.30 (Shellsol D70, aliphatic) to 2.75 (Solvesso 100, aromatic).

The effect of the initial zinc and extractant concentrations on zinc extraction was examined. Experiments were carried out at $20^{\circ} \mathrm{C}$ by contacting the undiluted passivation bath and the bath diluted at $50 \%$ and $75 \%$ with water and organic phases of 5-20\% v/v Cyanex 272 in Shellsol D70. Fig. 1 shows that the variation of the initial zinc concentration has a slight influence on the $\mathrm{pH}_{50}$ value, though at less acidic $\mathrm{pH}$ values (i.e. around 3.0) the apparent extraction order is $\mathrm{PB} / 4>\mathrm{PB} / 2>\mathrm{PB}$, that is, the more dilute zinc concentration

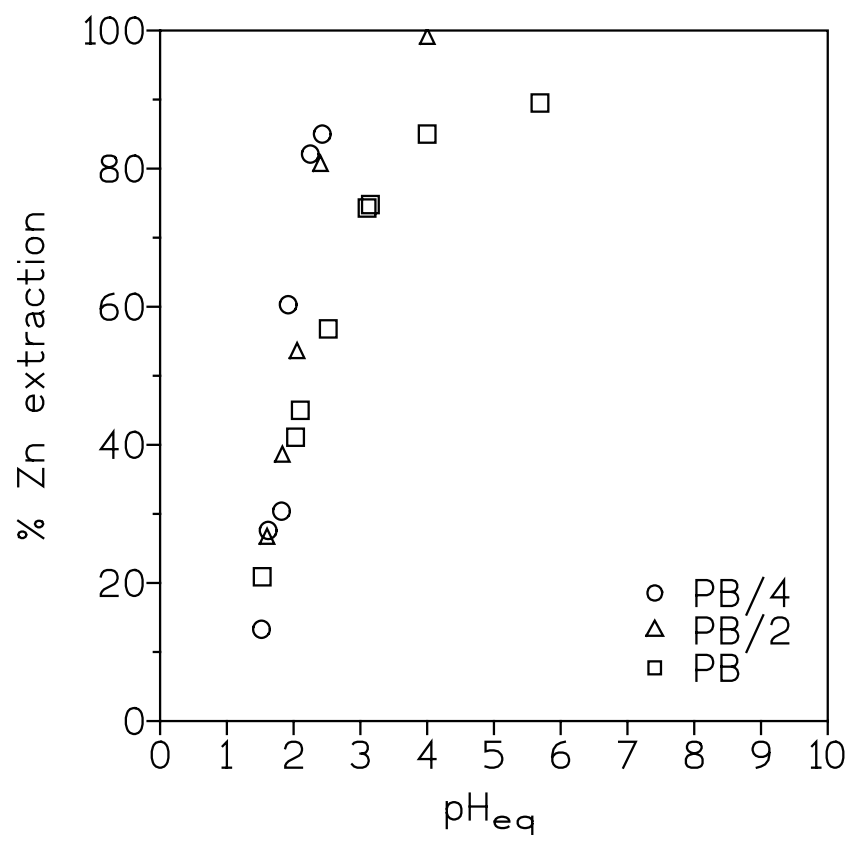

Fig. 1. Zinc extraction by Cyanex 272 at various initial metal concentrations. Equilibration time $10 \mathrm{~min}$. O/A ratio 1 . See Table 1 for metal concentrations. 
the higher percentage of zinc extraction at a fixed $\mathrm{pH}$ value. Near complete zinc extraction can be achieved at an equilibrium $\mathrm{pH}$ in the 3.5 range for the passivation bath diluted at $50 \%(\mathrm{~PB} / 2)$ or $75 \%(\mathrm{~PB} / 4)$.

In the case of varying the extractant concentration in the organic phase, the results shown that the variation in the initial Cyanex 272 concentration has an influence on zinc extraction (Fig. 2). The increase in the extractant concentration shifts the extraction curve to the left as expected from the general extraction equilibrium shown below.

Zinc extraction by acidic extractants, like Cyanex 272, can be primarily described using the most simple approach represented by the next equilibrium:

$\mathrm{Zn}_{\mathrm{aq}}^{2+}+2 \mathrm{HR}_{\text {org }} \Leftrightarrow \mathrm{R}_{2} \mathrm{Zn}_{\text {org }}+2 \mathrm{H}_{\mathrm{aq}}^{+}$

Thus, zinc extraction is achieved shifting the equilibrium to the right, whereas zinc stripping is carried out by shifting the equilibrium to the left.

It is worth to note here that the viscosity of the organic solutions increases, though not measured in this work, under high or near complete zinc loading.

Zinc stripping from loaded organic solutions was investigated using sulphuric acid solutions, medium which is typical of zinc electrowinning operation.

The influence of equilibration time on zinc stripping was investigated using organic solutions of $10 \%$ v/v Cyanex 272 in Shellsol D70 loaded with $5.8 \mathrm{~g} / \mathrm{L} \mathrm{Zn}$ and aqueous solutions of $1 \mathrm{M}$ sulphuric acid. Temperature was of $20^{\circ} \mathrm{C}$, whereas the $\mathrm{O} / \mathrm{A}$ ratio was 1 .

Equilibrium was reached very quickly, $5 \mathrm{~min}$, with no appreciable change in the percentage of metal stripped at longer equilibration times, that is, $1 \mathrm{~h}$, thus, using the above experimental conditions the percentage of zinc stripping is near $90 \%$.

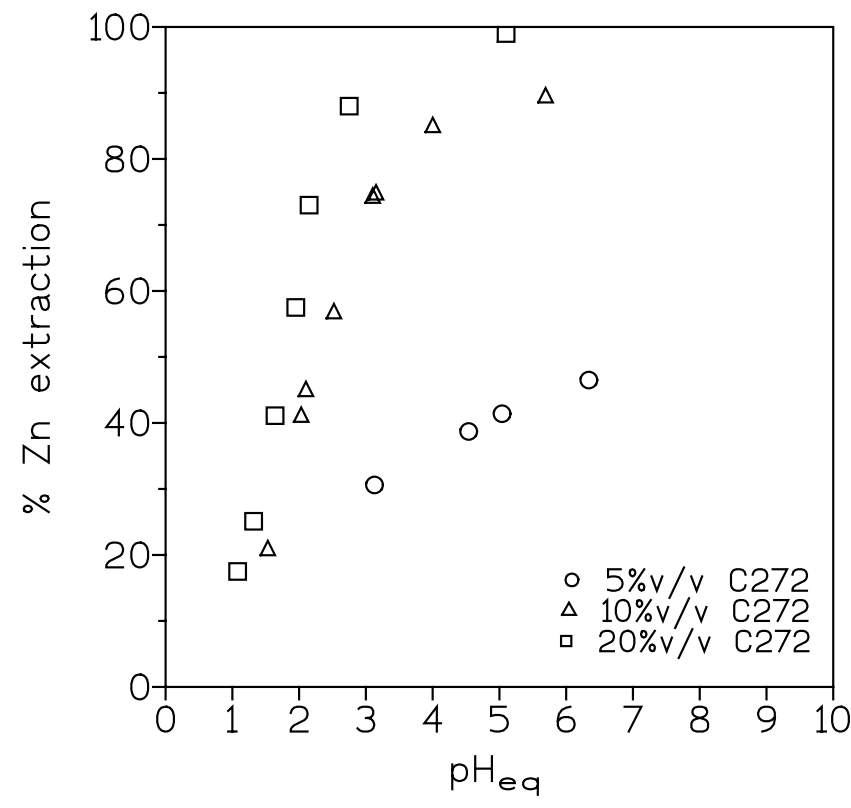

Fig. 2. Zinc extraction by Cyanex 272 at various initial extractant concentrations. Aqueous phase: undiluted passivation bath (PB). Equilibration time $10 \mathrm{~min}$. O/A ratio 1.
The effect of sulphuric acid concentration on zinc stripping was also investigated using organic solutions of 10\% v/v Cyanex 272 in Shellsol D70 loaded with $4.7 \mathrm{~g} / \mathrm{L} \mathrm{Zn}$.

From results presented in Table 3 , it can be concluded that the increase in the sulphuric acid concentration increased the percentage of zinc stripped, moreover, as the sulphuric acid concentration increases the less the stages for the complete zinc removal from the metal-loaded organic phase.

Results obtained from this investigation also shown that the concentration of zinc loaded into the organic phase influences the percentage of zinc stripped, that is, the higher the metal concentration loaded in the organic solution the less the percentage of zinc stripped by the sulphuric acid solution (Table 4). In this series of experiments a $2 \mathrm{M}$ sulphuric acid solution was used as strippant for zinc.

Furthermore, the effect of varying the O/A volume ratios on zinc stripping had been investigated using an organic solution of $10 \% \mathrm{v} / \mathrm{v}$ Cyanex 272 in Shellsol D70 loaded with $7.9 \mathrm{~g} / \mathrm{L} \mathrm{Zn}, 57.6 \mathrm{mg} / \mathrm{L}$ Fe and $0.11 \mathrm{~g} / \mathrm{L} \mathrm{Cr}$, and a $2 \mathrm{M}$ sulphuric acid strip solution. Results obtained from this set of experiments are summarized in Table 5, it can be seen that the concentration of zinc in the strip solution can be increased

Table 3

Influence of sulphuric acid concentration on zinc stripping

\begin{tabular}{llc}
\hline Sulphuric acid & Stage & \% Zn stripping \\
\hline $0.5 \mathrm{M}$ & 1 & 83.9 \\
& 2 & 10.4 \\
& 3 & 0.9 \\
$1.0 \mathrm{M}$ & 1 & 91.1 \\
$2.0 \mathrm{M}$ & 1 & 99.8 \\
& 2 & 0.2 \\
\hline
\end{tabular}

Equilibration time $10 \mathrm{~min}$. Temperature $20^{\circ} \mathrm{C}$. O/A ratio 1.

Table 4

Influence of zinc concentration loaded into the organic phase in metal stripping

\begin{tabular}{lc}
\hline Zinc in the organic solution & $\%$ Zn stripping \\
\hline $2.4 \mathrm{~g} / \mathrm{L}$ & $>99.0$ \\
$9.1 \mathrm{~g} / \mathrm{L}$ & 58.3 \\
\hline
\end{tabular}

Organic phase: $20 \%$ v/v Cyanex 272 in Shellsol D70. Temperature $20^{\circ} \mathrm{C}$. Equilibration time: $10 \mathrm{~min}$. O/A ratio 1.

Table 5

Effect of varying the O/A volume ratios on zinc stripping

\begin{tabular}{lll}
\hline O/A ratio & $\begin{array}{l}{[\mathrm{Zn}], \mathrm{g} / \mathrm{L}} \\
\text { aqueous phase }\end{array}$ & $\begin{array}{l}{[\mathrm{Zn}], \mathrm{g} / \mathrm{L}} \\
\text { organic phase }\end{array}$ \\
\hline 2 & 13.0 & 1.4 \\
4 & 22.8 & 2.2 \\
5 & 26.5 & 2.6 \\
7 & 31.5 & 3.4 \\
\hline
\end{tabular}

Temperature: $20^{\circ} \mathrm{C}$. Equilibration time: $10 \mathrm{~min}$. 
to more than $30 \mathrm{~g} / \mathrm{L}$, that is nearly four times its concentration in the corresponding metal-loaded organic phase, after equilibration with the acidic solution.

\subsection{Iron}

Basically speaking, iron is extracted in percentages exceeding always $95 \%$ for the $\mathrm{pH}$ values (around 2.5-3.0) at which zinc is extracted. The extraction of iron(III) by Cyanex 272 is also related to the shift of the next equilibrium to the right:

$\mathrm{Fe}_{\mathrm{aq}}^{3+}+3 \mathrm{HR}_{\text {org }} \Leftrightarrow \mathrm{FeR}_{3_{\text {org }}}+3 \mathrm{H}_{\text {aq }}^{+}$

and by shifting the equilibrium to the left, iron is released to the stripping solution.

Several remarks obtained from this investigation are:

- iron extraction equilibrium is reached within $15 \mathrm{~min}$ of contact,

- the increase of temperature influences iron extraction in the same manner that in the case of zinc,

- iron is stripped with sulphuric acid in percentages also exceeding $95 \%$.

\subsection{Chromium}

Against zinc and iron behaviour, this element is poorly extracted (less than 7\%) by Cyanex 272 at the $\mathrm{pH}$ values in which the other two elements do. The metal is also stripped with sulphuric acid. Similar to the case of zinc(II) and iron(III) (Eqs (1) and (2)), the extraction of chromium(III) can be related to a cation exchange reaction, whereas the stripping of the metal from $\mathrm{Cr}(\mathrm{III})$-loaded organic solutions is carried out by shifting the equilibrium to the left using acidic solutions as strip phases.

\subsection{Extraction-stripping cycles}

To investigate the re-use of a given organic solution, extraction-stripping studies were carried out on the same organic solution of $20 \% \mathrm{v} / \mathrm{v}$ Cyanex 272 in Shellsol D70, the aqueous feed solution was the undiluted passivation bath,

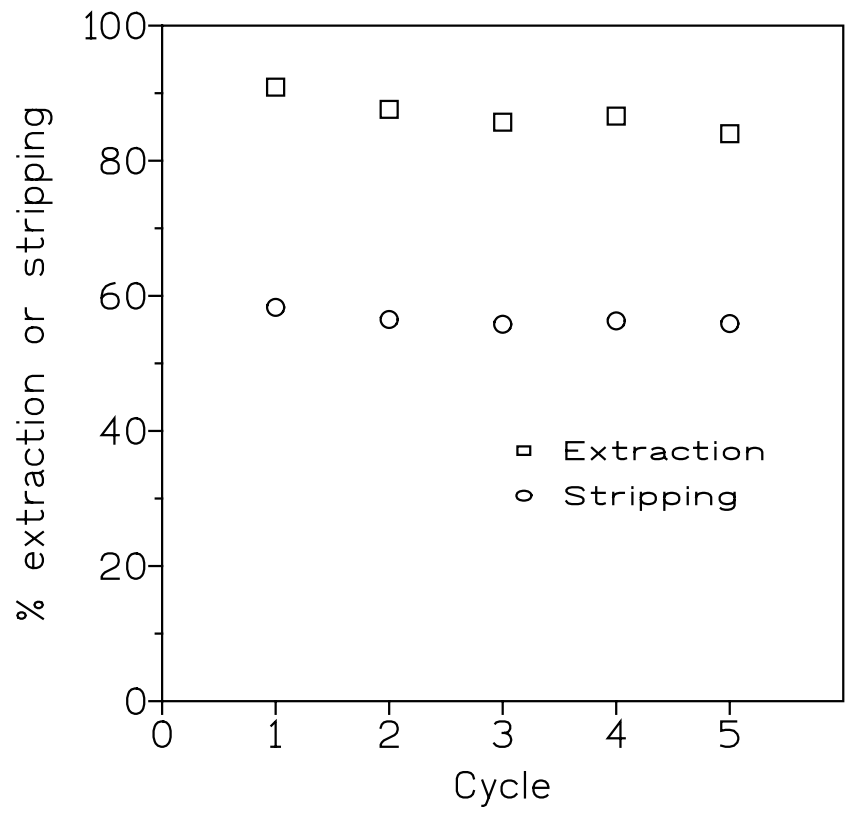

Fig. 3. Zinc extraction and stripping under successive cycles.

whereas the strippant was a $2 \mathrm{M}$ sulphuric acid solution. In all the cycles, the temperature was maintained at $20^{\circ} \mathrm{C}$ for extraction and stripping, and also the equilibration time was of $10 \mathrm{~min}$ for each stage, using in all the cases $\mathrm{O} / \mathrm{A}$ volumes ratio of 1 .

Results obtained from this set of experiments are shown in Fig. 3. It was found that after five cycles, nearly $90 \%$ of zinc was transferred from the aqueous solution to the organic phase at an equilibrium $\mathrm{pH}$ value of $2.9 \pm 0.1$, thus, with no loss of the initial extraction efficiency. Furthermore, nearly $60 \%$ of the extracted zinc was stripped from the metal-loaded organic solution using one step and $2 \mathrm{M}$ sulphuric acid as stripping phase.

\section{Conclusions}

Cyanex 272 is effectively used to extract zinc from chromium passivation baths. The extraction is mainly $\mathrm{pH}$ dependent and it is also better to extract with organic solutions

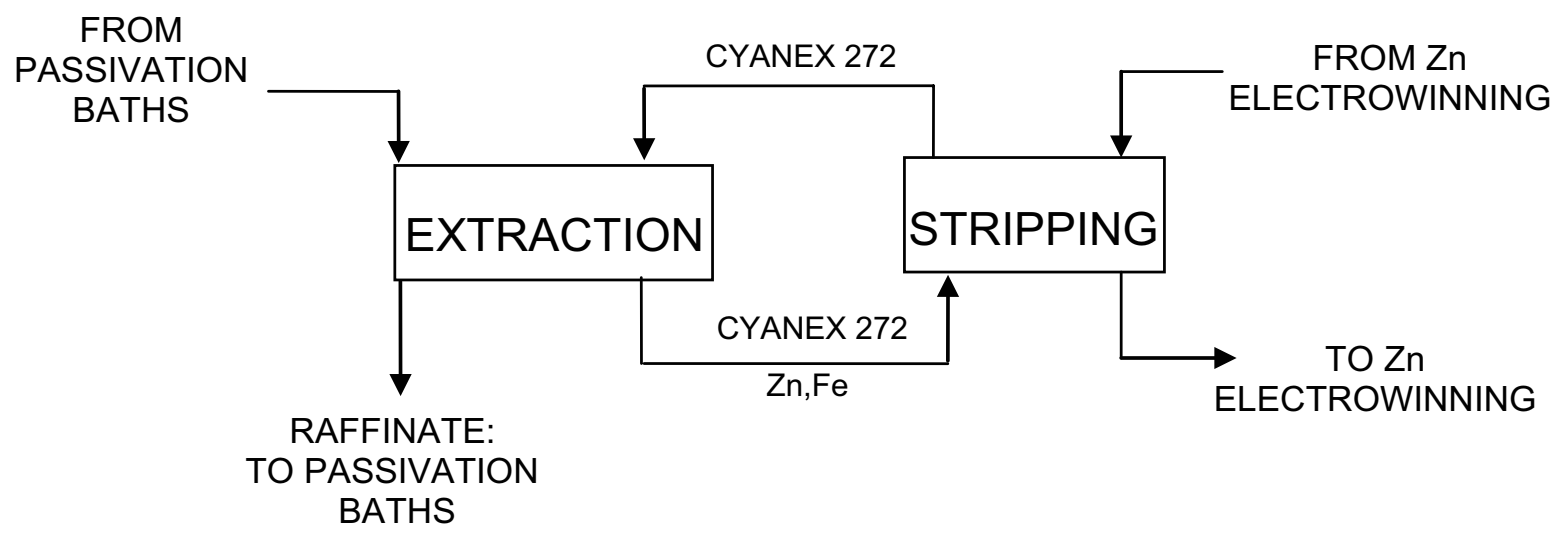

Fig. 4. Schematic flowsheet for the treatment of chromium(III) spent passivation baths using Cyanex 272 as extractant. 
with an extractant concentration of no less than $10 \% \mathrm{v} / \mathrm{v}$ to obtain proper zinc recoveries (i.e. around $90 \%$ ) at $\mathrm{pH}$ values in the 2.5-3.5 range. Zinc is stripped with acidic strip solutions, though the percentage of zinc stripped in one step is dependent upon the concentration of the metal in the loaded organic solution and also in the acid concentration of the strip solution.

Iron is near quantitatively extracted at the $\mathrm{pH}$ values in which zinc did and also it is stripped with the acidic solutions.

The extraction of chromium is near marginal, and basically the element remained in the raffinate obtained from the extraction operation.

Based on batch equilibrium results, a unit of three mixer settlers (one for extraction and two for stripping) is recommended for the treatment of spent passivation baths, using an organic phase of 20\% v/v Cyanex 272 in Shellsol D70, and return electrolyte as strip solution (Fig. 4). The exiting zinc-loaded strip solution can be further processed by electrowinning, since the presence of iron is not detrimental for the operation, in order to recover zinc as metal zinc $[19,20]$.

It is also advisable not to work with organic phases with a high zinc content or with organic solutions with near their zinc full load, since in these conditions, the viscosity of the organic solution dramatically increases with a loss in the general performance of the system.

\section{Acknowledgements}

Authors thanked Cytec Ind. for providing a sample of Cyanex 272. Also to the CSIC (Spain) for support.

\section{References}

[1] A.A. Baba, F.A. Adekola, Beneficiation of a Nigerian sphalerite mineral: solvent extraction of zinc by Cyanex®272 in hydrochloric acid, Hydrometallurgy, 109 (2011) 187-193.

[2] C. David, S. Engelbrecht, G.N. Diaz, F.R. Sanchez, A. Belen Mejias, Skorpion Zinc-Lessons Learnt in the Operation of the Modified Zincex Solvent Extraction Process, F.L. Valenzuela, B.A. Moyer, Eds., Proc. XIX International Solvent Extraction Conference (ISEC 2011), Gecamin, Santiago de Chile, 2011, p. 30.

[3] D. Dreisinger, F. Xie, T. Glück, K. Marte, Solvent Extraction of Boleo Solutions with Cyanex 272 and Ionquest 290, F.L. Valenzuela, B.A. Moyer, Eds., Proc. XIX International Solvent Extraction Conference (ISEC 2011), Gecamin, Santiago de Chile, 2011, p. 27.

[4] E. Vahidi, F. Rashchi, D. Moradkhani, Recovery of zinc from an industrial zinc leach residue by solvent extraction using D2EHPA, Miner. Eng., 22 (2009) 204-206.

[5] D.D. Pereira, S.D. Ferreira Rocha, M.B. Mansur, Recovery of zinc sulphate from industrial effluents by liquid-liquid extraction using D2EHPA (di-2-ethylhexylphosphoric acid), Sep. Purif. Technol., 53 (2006) 89-96.

[6] J.E. Silva, A.P. Paiva, D. Soares, A. Labrincha, F. Castro, Solvent extraction applied to the recovery of heavy metals from galvanic sludge, J. Hazard. Mater., 120 (2005) 113-118.

[7] Y.K.P. Sze, L. Xue, Extraction of zinc and chromium(III) and its application to treatment of alloy electroplating wastewater, Sep. Sci. Technol., 38 (2003) 405-425.

[8] I. Ortiz, E. Bringas, M.F. San Roman, A. Urtiaga, Selective separation of zinc and iron from spent pickling solutions by membrane-based solvent extraction: process viability, Sep. Sci. Technol., 39 (2004) 2441-2455.

[9] M. Regel-Rosocka, A review of methods of regeneration of spent pickling solutions from steel processing, J. Hazard. Mater., 177 (2010) 57-69.

[10] M. Tian, F. Mu, Q. Jia, X. Quan, W. Liao, Solvent extraction studies of zinc(II) and cadmium(II) from chloride medium with mixtures of neutral organophosphorus extractants and amine extractants, J. Chem. Eng. Data, 56 (2011) 2225-2229.

[11] F.J. Alguacil, I. Garcia-Diaz, F.A. Lopez, O. Rodríguez, A. Urien, I. Padilla, in: J. Mun, H. Sim, Eds., Handbook of Ionic Liquids: Properties, Applications and Hazards, Nova Science Publ., New York, 2012, pp. 257-280 (Chapter 10).

[12] L. Bulgariu, D. Bulgariu, The partition behaviour of $\mathrm{Zn}(\mathrm{II})$ using halide ions extractants in aqueous PEG-based two-phase systems, Sep. Sci. Technol., 42 (2007) 1093-1106.

[13] A.P. de los Rios, F.J. Hernandez-Fernandez, L.J. Lozano, S. Sanchez, J.L. Moreno, C. Godinez, Removal of metal ions from aqueous solutions by extraction with ionic liquids, J. Chem. Eng. Data, 55 (2010) 605-608.

[14] A.P. de los Rios, F.J. Hernandez-Fernandez, F.J. Alguacil, L.J. Lozano, A. Ginesta, I. Garcia-Diaz, S. Sanchez-Segado, F.A. Lopez, C. Godinez, On the use of imidazolium and ammonium-based ionic liquids as green solvents for the selective recovery of $\mathrm{Zn}(\mathrm{II}), \mathrm{Cd}(\mathrm{II}), \mathrm{Cu}(\mathrm{II})$, and $\mathrm{Fe}(\mathrm{III})$ from hydrochloride aqueous solutions, Sep. Purif. Technol., 97 (2012) 150-157.

[15] M. Regel-Rosocka, Extractive removal of zinc(II) from chloride liquors with phosphonium ionic liquids/toluene mixture as novel extractants, Sep. Purif. Technol., 66 (2009) 19-24.

[16] M. Regel-Rosocka, M. Wisniewski, Selective removal of zinc(II) from spent pickling solutions in the presence of iron ions with phosphonium ionic liquid Cyphos IL 101, Hydrometallurgy, 110 (2011) 85-90.

[17] A. Urtiaga, E. Bringas, R. Mediavilla, I. Ortiz, The role of liquid membranes in the selective separation and recovery of zinc for the regeneration of $\mathrm{Cr}(\mathrm{III})$ passivation baths, J. Membr. Sci., 356 (2010) 88-95.

[18] N. Diban, V. Garcia, F. Alguacil, I. Ortiz, A. Urtiaga, Temperature enhancement of zinc and iron separation from chromium(III) passivation baths by emulsion pertraction technology, Ind. Eng. Chem. Res., 51 (2012) 9867-9874.

[19] G.M. Ritcey, A.W. Ashbrook, Solvent Extraction: Principles and Applications to Process Metallurgy. Part II, Elsevier, Amsterdam, 1979.

[20] N. Diban, R. Mediavilla, A. Urtiaga, I. Ortiz, Zinc recovery and water sludge minimization from chromium passivation baths, J. Hazard. Mater., 192 (2011) 801-807. 